\title{
CD19 CAR-T expressing PD-1/CD28 chimeric switch receptor as a salvage therapy for DLBCL patients treated with different CD19-directed CAR T-cell therapies
}

Yun Liang ${ }^{1 \dagger}$, Hui Liu ${ }^{1 \dagger}$, Zheming Lu ${ }^{2 \dagger}$, Wen Lei ${ }^{1}$, Chaoting Zhang ${ }^{2}$, Ping Li ${ }^{3}$, Aibin Liang ${ }^{3 *}$, Ken H. Young ${ }^{4 *}$ and Wenbin Qian ${ }^{1,5,6^{*}}$

\begin{abstract}
CD19-targeted chimeric antigen receptor T (CART) cell therapy is a promising option to treat relapsed/refractory diffuse large B-cell lymphoma (R/R DLBCL). However, the majority of CART-treated patients will eventually progress and require salvage treatment, for which there is no current standard. In this study, we analyzed data from 6 patients with R/R DLBCL who experienced progression following CD19-CART therapy, and then received CD19-specific CART cells that express a PD-1/CD28 chimeric switch-receptor (CD19-PD-1/CD28-CART) as salvage therapy at our institution. After the second infusion of CART cells, 3 of 6 patients achieved complete remissions and the duration of the response of responsive patients ranged from 8 to 25 months. One patient showed a stable disease. In contrast, 2/6 patients died on 60 days because of progression disease. Importantly, no severe neurologic toxicity or cytokine release syndrome was observed. These data suggest that CD19-PD-1/CD28-CAR-T cells, a novel anti-CD19 CAR-T cell therapy, elicit a potent and durable anticancer response, and can be used in the post-CD19-CART failure setting.
\end{abstract}

Keywords: DLBCL, CART cell therapy, PD-1/CD28 chimeric switch receptor, Salvage therapy

\section{To the Editor:}

CD19-specific CAR $\mathrm{T}$ cell therapy has significantly improved the outcome of patients with R/R DLBCL, resulting in durable remissions in approximately $40 \%$ of heavily pretreated patients. Despite these encouraging results, nearly half of the patients could not achieve

\footnotetext{
*Correspondence: lab7182@tongji.edu.cn; ken.young@duke.edu; qianwb@zju.edu.cn

${ }^{\dagger}$ Yun Liang, Hui Liu and Zheming Lu are co-first author

${ }^{1}$ Department of Hematology, The Second Affiliated Hospital, College of Medicine, Zhejiang University, Hangzhou, Zhejiang, People's Republic of China

${ }^{3}$ Department of Hematology, Tongji Hospital of Tongji University, Shanghai, People's Republic of China

${ }^{4}$ Hematopathology Division and Department of Pathology, Duke University Medical Center and Cancer Institute, Durham, NC, USA Full list of author information is available at the end of the article
}

durable response after CD19-CAR T therapy and a significant proportion of patients will eventually relapse and develop treatment-refractory, fatal disease [1-4]. Recently, Spiegel et al. [5] reported on outcomes of large B-cell lymphoma patients who experienced progression following CD19-CAR T (Axicabtagene ciloleucel, axicel). The results showed that median overall survival (OS) from date of progression disease was 180 days (95\% CI 105-242). Until now, there is no recommended therapeutic schedule for this fatal disease.

Six patients who relapsed or were refractory to CD19CAR $\mathrm{T}$ therapy have been treated with CD19-PD-1/ CD28-CAR-T, a novel anti-CD19 CAR-T cell therapy [6], on compassionate-use basis at our institution between January 2018 and August 2019. This retrospective study was approved by the Ethics Committee of the Second original author(s) and the source, provide a link to the Creative Commons licence, and indicate if changes were made. The images or other third party material in this article are included in the article's Creative Commons licence, unless indicated otherwise in a credit line to the material. If material is not included in the article's Creative Commons licence and your intended use is not permitted by statutory regulation or exceeds the permitted use, you will need to obtain permission directly from the copyright holder. To view a copy of this licence, visit http://creativecommons.org/licenses/by/4.0/. The Creative Commons Public Domain Dedication waiver (http://creativeco mmons.org/publicdomain/zero/1.0/) applies to the data made available in this article, unless otherwise stated in a credit line to the data. 
Affiliated Hospital, Zhejiang University (Hangzhou, China) and conducted in accordance with the principles of the Declaration of Helsinki. As of October 1, 2020, the median follow-up time was 14 months. Six consecutive patients were enrolled. Patients ranged from 47 to 63 years of age and had received prior CD19-CAR T therapy with CD28-based or 4-1BB-based CAR T cells. Three of the six patients were refractory to the first CAR $\mathrm{T}$ treatment, and two patients had partial remission (PR) with response duration of 3 and 4 months, respectively.
One patient had a CR duration of 30 months before relapse (Table 1 and Fig. 1a). CD19-PD-1/CD28-CAR$\mathrm{T}$ cells manufactured from the leukapheresed or cryopreservated autologous peripheral blood mononuclear cells were successful for all 6 patients. After failure of first CAR T therapy, patients received conditioning chemotherapy containing cyclophosphamide $500 \mathrm{mg} / \mathrm{m}^{2}$ and fludarabine $30 \mathrm{mg} / \mathrm{m}^{2}$ daily on days -5 to -3 , and followed by a single intravenous infusion of CD19-PD-1/ CD28-CAR-T as a salvage treatment for refractory or

Table 1 Clinical characteristics and post-CAR T outcomes

\begin{tabular}{|c|c|c|c|c|c|c|}
\hline Patient Number & 1 & 2 & 3 & 4 & 5 & 6 \\
\hline Age (years) & 51 & 51 & 53 & 47 & 56 & 63 \\
\hline Sex & Male & Male & Female & Female & Female & Male \\
\hline Diagnosis/subtype & TFL & DLBCL/GCB & DLBCL/non-GCB & HGBL (Triple hit) & DLBCL/non-GCB & DLBCL/non-GCB \\
\hline ECOG PS 1 & 1 & 3 & 1 & 3 & 3 & 1 \\
\hline Prior therapy & $\begin{array}{l}\text { R-CHOP; 2-HyperC- } \\
\text { VAD-A }\end{array}$ & $\begin{array}{l}\text { R-CHOP; } \\
\text { R-BEAM + ASCT }\end{array}$ & $\begin{array}{l}\text { R-CHOP; R-GDP; } \\
\text { R2-COP + mitox- } \\
\text { antrone; } \\
\text { BEAM + ASCT }\end{array}$ & $\begin{array}{l}\text { CHOP; R- EPOCH; } \\
\text { R-DA-EPOCH; } \\
\text { DHAP }\end{array}$ & $\begin{array}{l}\text { R- EPOCH; R-GeMox; } \\
\text { ICE R-COP'; } \\
\text { lbrutinib }\end{array}$ & $\begin{array}{l}\text { R-CHOP; R-GDP; } \\
\text { R2-MINE; } \\
\text { R-DHAP }\end{array}$ \\
\hline Disease Stage ${ }^{1}$ & 4 & 3 & 4 & 4 & 4 & 3 \\
\hline B Symptom ${ }^{1}$ & $A$ & A & B & A & $A$ & A \\
\hline PD-L $1^{1}$ & $20 \%$ & $25 \%$ & Negative & Negative & Negative & Negative \\
\hline $\mathrm{Ki}-67^{1}$ & $80 \%$ & $50 \%$ & $80 \%$ & $100 \%$ & $40 \%$ & $80 \%$ \\
\hline IPI Score ${ }^{1}$ & 2 & 3 & 3 & 3 & 4 & 2 \\
\hline \multicolumn{7}{|l|}{ First CAR-T } \\
\hline $\begin{array}{l}\text { Costimulatory } \\
\text { domain }\end{array}$ & $4-1 B B$ & $4-1 \mathrm{BB}$ & CD28 & CD28 & $4-1 \mathrm{BB}$ & $4-1 \mathrm{BB}$ \\
\hline Dose $\left(10^{6} / \mathrm{kg}\right)$ & 0.50 & 1.00 & 0.88 & 1.78 & 4.00 & 2.00 \\
\hline Response & PR & PD & PD & PD & PR & $C R$ \\
\hline DOR (Month) & 4 & NA & NA & NA & 3 & 30 \\
\hline \multicolumn{7}{|l|}{ Second CAR-T } \\
\hline ECOG PS & 2 & 4 & 1 & 4 & 3 & 1 \\
\hline Dose $\left(10^{6} / \mathrm{kg}\right)$ & 0.32 & 0.63 & 0.50 & 2.90 & 4.00 & 2.00 \\
\hline Response & PD & ED & $C R$ & ED & $C R$ & $\mathrm{CR}$ \\
\hline DOR (Month) & NA & NA & 25 & NA & 8 & 14 \\
\hline PBMC Source & Leukapheresis & Cryopreservation & Cryopreservation & Cryopreservation & Leukapheresis & Leukapheresis \\
\hline $\begin{array}{l}\text { Time for CAR-T } \\
\text { culture (Day) }\end{array}$ & 15 & 14 & 14 & 13 & 14 & 12 \\
\hline Naïve T (\%) & 1.89 & 29.85 & 25.35 & 51.9 & 31.25 & 28.64 \\
\hline TCM T (\%) & 60.48 & 26.84 & 40.49 & 42.89 & 47.97 & 13.66 \\
\hline TEM T (\%) & 1.14 & 21.35 & 23.26 & 3.81 & 13.61 & 13.16 \\
\hline TEMRA T (\%) & 36.49 & 21.96 & 10.90 & 1.40 & 7.17 & 44.55 \\
\hline
\end{tabular}

ASCT, autologous stem cell transplant; $\mathrm{CHOP}$, cyclophosphamide, adriamycin, vincristine, prednisone; COP, cyclophosphamide, vincristine, prednisone; EPOCH, etoposide, prednisone, vincristine, cyclophosphamide, doxorubicin; BEAM, carmustine, etoposide, cytarabine, melphalan; GDP, gemcitabine, dexamethasone, cisplatin; GEMOX, gemcitabine, oxaliplatin; ICE, ifosfamide, carboplatin, etoposide; HyperCVAD, cyclophosphamide, vincristine, doxorubicin, dexamethasone; DHAP, dexamethasone, high dose cytarabine, cisplatin; ICE, ifosfamide, carboplatin, etoposide; MINE, mesna, ifosfamide, mitoxantrone, etoposide; R, rituximab; R2, rituximab combined with lenalidomide; DLBCL, diffuse large B cell lymphoma; ECOG PS, Eastern Cooperative Oncology Group performance status; IPI, International Prognostic Index; GCB, germinal center B cell; TFL, transformed follicular lymphoma; DLBCL, diffuse large B-cell lymphoma; HGBL, high grade B-cell lymphoma; Triple hit, MYC, BCL2 and BCL6 rearrangements. DOR, Duration of Response; TCM, T cells with central memory; TEM, T cells with effector memory; TEMRA, terminally differentiated effector T cells

1 These data were collected before first CAR-T

2 The chemotherapy regimens were conducted after first CAR-T 


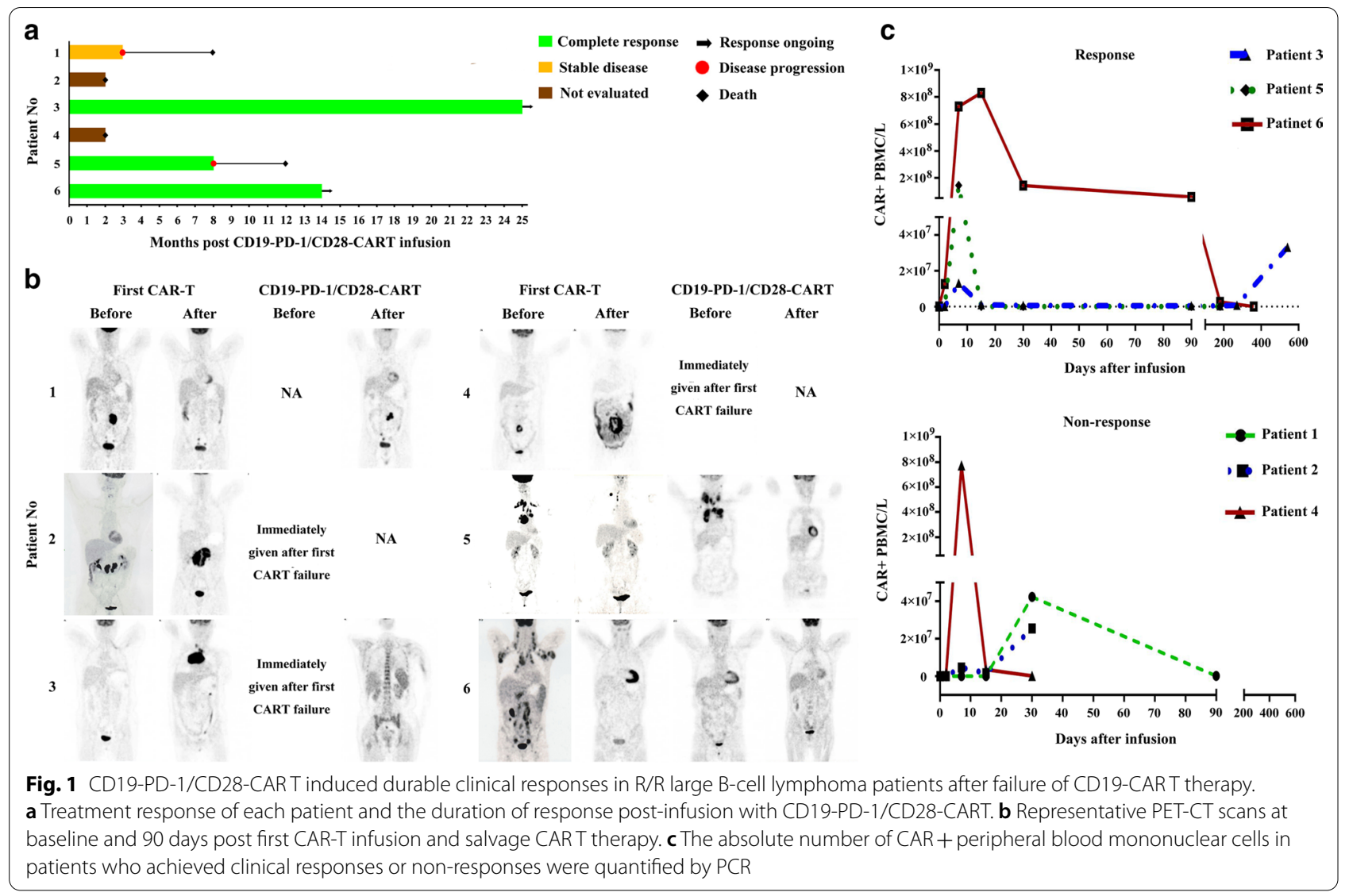

relapsed disease. The therapeutic doses of CAR T range from $0.32 \times 10^{6}$ to $4 \times 10^{6} / \mathrm{kg}$ of body weight. A total of 90 related adverse events occurring within 30 days of CAR-T infusion were recorded between grade 1 and 4 (Additional file 1: Table S1). Overall, 3/6 patients experienced grade 1 CRS, Patient 2 experienced grade 2 CRS, and Patient 4 and Patient 6 had both grade 2 CRS and grade 3 ICANS (immune effector cell-associated neurotoxicity syndrome). Serum cytokine levels were detected in all patients during the first month following second CAR-T therapy (Additional file 2: Figure S1). IL-6, IL-4, IL-2, and TNF $\alpha$ were elevated in Patient 1. Patient 4 who experienced both grade 2 CRS and grade 3 ICANS exhibited increased levels of IL-6, IL-4, IL-2, IL-17A, and IFN $\gamma$, but such increased levels were not observed in Patient 6 . Four cases of CRS resolved fully by supportive treatment while the 2 patients suffered from both CRS and ICANS resolved completely after treatment with supportive care, tocilizumab and glucocorticoids. The response was evaluated with FDG-PET-CT at 3 months after infusion (Fig. 1b), according to the International Working Group Response Criteria for Malignant Lymphoma. As shown in Table 1 and Fig. 1, three of six patients achieved a CR, and one patient showed stable disease. In contrast, 2/6 patients died on 60 days because of progression disease. Two of three patients achieving CR maintained ongoing response on the date for the last visit. But, another one relapsed within 8 months and eventually died 12 months after CAR T treatment. The presence of CAR-T cells in patients' blood was monitored by qPCR. The number of blood $\mathrm{CAR}^{+}$cells peaked within 2 weeks after infusion. However, peak blood $\mathrm{CAR}^{+}$cell numbers did not differ significantly between patients with response and those without response. Interestingly, $\mathrm{CAR}^{+}$cell numbers dropped rapidly after peaking but increased significantly by day 540 after CAR T treatment in Patient 3 who achieved durable remission with long, treatment-free interval (Fig. 1c).

Treatment options are limited for DLBCL patients when disease fails to respond to or relapses after CD19 CAR-T cell therapy. Novel therapies with different mechanisms of actions are critical to improve unmet clinical needs and the outcome of these patients. Alternative CD19-specific CAR-T product may be an active salvage therapy although no clinical trials have defined the optimal approach. A recent study evaluated the efficacy of axi-cel, a CD28 costimulatory-based CD19-CAR $\mathrm{T}$, as salvage therapy after failure of tisagenlecleucel or 
investigational CD19 CAR-T with 4-1BB costimulation in patients with DLBCL. One of three patients achieved CR, but died 180 days after axi-cel treatment because of progressive disease while two of three patients were refractory [7]. In another clinical study, second infusion of CD19-CAR $T$ was used as salvage treatment after failure of first CD19 CAR T-cell therapy. Of 21 Non-Hodgkin lymphoma (NHL) patients, the overall response rate after the second CAR T was $52 \%$ (CR, $n=4 ; \mathrm{PR}, n=7$ ) [8]. In the present study, 3 of 6 patients achieved CRs, 2 of 3 CRs are ongoing, suggesting that CD19-PD-1/CD28-CAR-T elicit a potent and durable anticancer response, and can be used in the post-CD19 CAR $\mathrm{T}$ failure setting. However, we did not find an association between the costimulatory domain of CAR $\mathrm{T}$ and disease control (Table 1).

CAR T cell efficacy can be enhanced by using engineering strategies to address the challenge relating to $\mathrm{T}$ cell exhaustion induced by PD-1/PD-L1 pathway [9-11]. Until now, few cases report rare lymphoma patients who could obtain better efficacy by a combination of CAR-T cell therapy and PD-1 blockade $[10,12]$. Recently, we have reported that CD19-PD-1/CD28CAR $T$ cells exhibited a superior capability of killing $\mathrm{PD}-\mathrm{L}^{+} \mathrm{B}$-cell lymphoma cells in vitro and in vivo relative to the prototype, CD19-CAR T cells. We also demonstrated that this therapy had a favorable safety profile and induced durable clinical responses in the patients with $\mathrm{PD}-\mathrm{L}^{+}{ }^{+} \mathrm{R} / \mathrm{R}$ DLBCL [6]. An interesting aspect of the current study was that CD19-PD-1/CD28-CAR $\mathrm{T}$ was generally well-tolerated and resulted in a high response rate that was durable in $\mathrm{R} / \mathrm{R}$ large $\mathrm{B}$-cell lymphoma after failure of CD19-CAR T therapy. In conclusion, our data demonstrate the ability to augment CAR $\mathrm{T}$ cells targeting $\mathrm{CD} 19^{+}$lymphoma by co-expressing a chimeric PD-1/CD28 switch-receptor, and that this therapy has potential as a salvage treatment when first CAR T proves ineffective or resistant.

\section{Supplementary Information}

The online version contains supplementary material available at https://doi. org/10.1186/s13045-021-01044-y.

Additional file 1: Table S1. Treatment-emergent adverse events.

Additional file 2: Figure S1. Kinetics of serum cytokines. A-H. Fold change of listed serum cytokines obtained from patients at the indicated times was calculated relative to the baseline.

\section{Abbreviations}

DLBCL: Diffuse large B cell lymphomas; NHL: Non-Hodgkin lymphoma; PD-1: Programmed cell death 1; PD-L1: Programmed cell death 1 ligand; CART: Chimeric antigen receptor T; R/R DLBCL: Relapsed/refractory diffuse large B-cell lymphoma; CRs: Complete remissions; PR: Partial remission; OS: Overall survival; CRS: Cytokine release syndrome; ICANS: Immune effector cell-associated neurotoxicity syndrome.
Acknowledgements

Not applicable.

\section{Authors' contributions}

W. Qian, A. Liang, K. H. Young, and Z. Lu were responsible for conception, design and manuscript writing. Y. Liang, H. Liu, W. Lei, C. Zhang and P. Li were responsible for collection, analysis, and interpretation. All authors were involved at each stage of manuscript preparation and approved the final version. All authors read and approved the final manuscript.

\section{Funding}

This study was supported by funds from Translational Research Grant of NCRCH (2020ZKZC01), and the National Natural Science Foundation of China (No. 81830006, 81830004).

\section{Availability of data and materials}

All data generated or analyzed during this study are included in this paper and its Supplementary files.

\section{Ethics approval and consent to participate}

This study was approved by the Ethics Committee of the Second Affiliated Hospital, Zhejiang University (Hangzhou, China) and all patients provided written informed consent.

\section{Consent for publication}

Not applicable.

\section{Competing interests}

The authors declare that they have no competing interests.

\section{Author details}

${ }^{1}$ Department of Hematology, The Second Affiliated Hospital, College of Medicine, Zhejiang University, Hangzhou, Zhejiang, People's Republic of China. ${ }^{2}$ Key Laboratory of Carcinogenesis and Translational Research (Ministry of Education/Beijing), Laboratory of Biochemistry and Molecular Biology, Peking University Cancer Hospital and Institute, Beijing 100142, People's Republic of China. ${ }^{3}$ Department of Hematology, Tongji Hospital of Tongji University, Shanghai, People's Republic of China. ${ }^{4}$ Hematopathology Division and Department of Pathology, Duke University Medical Center and Cancer Institute, Durham, NC, USA. ${ }^{5}$ Institute of Hematology, Zhejiang University, Hangzhou 31003, Zhejiang, People's Republic of China. ${ }^{6}$ National Clinical Research Center for Hematologic Diseases, the First Affiliated Hospital of Soochow University, Suzhou, Jiangsu, People's Republic of China.

Received: 4 December 2020 Accepted: 3 February 2021

Published online: 16 February 2021

\section{References}

1. Wang H, Kaur G, Sankin Al, Chen F, Guan F, Zang X. Immune checkpoint blockade and CAR-T cell therapy in hematologic malignancies. J Hematol Oncol. 2019;12(1):59. https://doi.org/10.1186/s13045-019-0746-1.

2. Neelapu SS, Locke FL, Bartlett NL, Lekakis LJ, Miklos DB, Jacobson CA, et al. Axicabtagene ciloleucel CAR T-cell therapy in refractory large B-cell lymphoma. N Engl J Med. 2017;377(26):2531-44. https://doi.org/10.1056/ NEJMoa1707447.

3. Locke FL, Ghobadi A, Jacobson CA, Miklos DB, Lekakis LJ, Oluwole OO, et al. Long-term safety and activity of axicabtagene ciloleucel in refractory large B-cell lymphoma (ZUMA-1): a single-arm, multicentre, phase 1-2 trial. Lancet Oncol. 2019;20(1):31-42. https://doi.org/10.1016/S1470 -2045(18)30864-7.

4. Schuster SJ, Bishop MR, Tam CS, Waller EK, Borchmann P, McGuirk JP, et al. Tisagenlecleucel in adult relapsed or refractory diffuse large B-cell lymphoma. N Engl J Med. 2019;380(1):45-56. https://doi.org/10.1056/NEJMo a1804980.

5. Spiegel JY, Dahiya S, Jain MD, Tamaresis JS, Nastoupil L, Jacobs MT, et al. Outcomes of patients with large B-cell lymphoma progressing after Axicabtagene Ciloleucel. Blood. 2020. https://doi.org/10.1182/blood.20200 06245. 
6. Liu H, Lei W, Zhang C, Yang C, Wei J, Guo Q, et al. CD19-specific CAR-T cells that express a PD-1/CD28 chimeric switch-receptor is effective in patients with PD-L1 positive B-cell lymphoma. Clin Cancer Res. 2020. https://doi.org/10.1158/1078-0432.CCR-20-1457.

7. Chow VA, Gopal AK, Gauthier J, Tseng YD, Turtle CJ, Maloney DG, et al. Axicabtagene ciloleucel for relapsed or refractory lymphoma after prior treatment with a different CD19-directed CAR T-cell therapy. Blood Adv. 2020;4(19):4869-72. https://doi.org/10.1182/bloodadvances.2020002292.

8. Gauthier J, Bezerra ED, Hirayama AV, et al. Factors associated with outcomes after a second CD19-targeted CART-cell infusion for refractory B cell malignancies. Blood. 2020. https://doi.org/10.1182/blood.20200 06770.

9. Li S, Siriwon N, Zhang X, Yang S, Jin T, He F, et al. Enhanced cancer immunotherapy by chimeric antigen receptor-modified $T$ cells engineered to secrete checkpoint inhibitors. Clin Cancer Res. 2017;23(22):6982-92. https ://doi.org/10.1158/1078-0432.CCR-17-0867.

10. Chong EA, Melenhorst JJ, Lacey SF, Ambrose DE, Gonzalez V, Levine $\mathrm{BL}$, et al. PD-1 blockade modulates chimeric antigen receptor
(CAR)-modified T cells: refueling the CAR. Blood. 2017;129(8):1039-41. https://doi.org/10.1182/blood-2016-09-738245.

11. Hu W, Zi Z, Jin Y, Li G, Shao K, Cai Q, et al. CRISPR/Cas9-mediated PD-1 disruption enhances human mesothelin-targeted CAR T cell effector functions. Cancer Immunol Immunother. 2019;68(3):365-77. https://doi. org/10.1007/s00262-018-2281-2.

12. Wang J, Deng Q, Jiang YY, Zhang R, Zhu HB, Meng JX, et al. CAR-T 19 combined with reduced-dose PD-1 blockade therapy for treatment of refractory follicular lymphoma: A case report. Oncol Lett. 2019;18(5):4415-20. https://doi.org/10.3892/ol.2019.10783.

\section{Publisher's Note}

Springer Nature remains neutral with regard to jurisdictional claims in published maps and institutional affiliations.
Ready to submit your research? Choose BMC and benefit from:

- fast, convenient online submission

- thorough peer review by experienced researchers in your field

- rapid publication on acceptance

- support for research data, including large and complex data types

- gold Open Access which fosters wider collaboration and increased citations

- maximum visibility for your research: over $100 \mathrm{M}$ website views per year

At BMC, research is always in progress.

Learn more biomedcentral.com/submissions 